
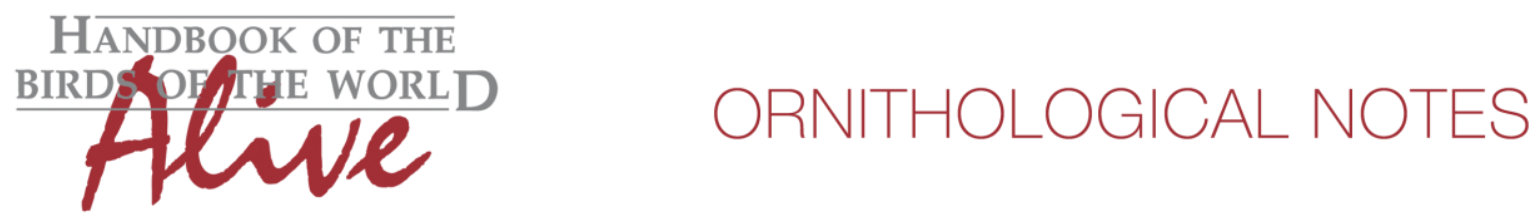

\title{
Notes on the vocalizations of Bran-colored Flycatcher (Myiophobus fasciatus)
}

Peter Boesman

In the following we briefly analyze and compare voice of the different races of Bran-colored Flycatcher (Myiophobus fasciatus). We also try to quantify the extent of any vocal differences using the criteria proposed by Tobias et al. (2010), as a support for taxonomic review. We have made use of sound recordings available on-line from Xeno Canto (XC).

There aren't that many recordings of dawn song available, and definitely not of all races. On the contrary, there are quite some recordings of day-time song available, a very typical and often heard long note followed by a trill. In the following I am analyzing only this daytime song.

There are clearly 3 vocal groups (Fig. 1):

Group 1: M. f. fasciatus M. f. saturatus M. f. auriceps M. f. flammiceps (no recordings of M. f. furfurosus).

$\begin{array}{ll}\text { Length 1st note } & 0.14-0.21 \mathrm{~s} \\ \text { min. note length } & 0.05-0.07 \mathrm{~s} \\ \text { max. freq. } & 3600-4700 \mathrm{~Hz} \\ \text { freq. range } & 2000-2900 \mathrm{~Hz} \\ \text { max. pace } & 0.058-0.088 \\ \text { \# of notes } & 7-18 \\ \text { min. freq. } & 1500-1820 \mathrm{~Hz}\end{array}$

Group 2: M. f. crypterythrus (SW Colombia, W Ecuador and NW \& N Peru)

\begin{tabular}{ll}
\hline Length 1st note & $0.21-0.25 \mathrm{~s}$ \\
min. note length & $0.09-0.14 \mathrm{~s}$ \\
max. freq. & $7300-10800 \mathrm{~Hz}$ \\
freq. range & $4500-7900 \mathrm{~Hz}$ \\
max. pace & $0.12-0.20$ \\
\# of notes & $5-11$ \\
min. freq. & $2400-2800 \mathrm{~Hz}$
\end{tabular}

Group 3: M. f. rufescens (W Peru and extreme N Chile)

Day-time song seems to be usually a duet, one bird emitting a trill without initial long note, the second bird uttering squeaky notes.

$\begin{array}{ll}\text { Length 1st note } & 0.05-0.06 \mathrm{~s} \text { ?? } \\ \text { min. note length } & 0.04-0.05 \mathrm{~s} \\ \text { max. freq. } & 3050-4200 \mathrm{~Hz} \\ \text { freq. range } & 1150-2400 \mathrm{~Hz} \\ \text { max. pace } & 0.06-0.074 \\ \text { \# of notes } & 11-32 \\ \text { min. freq. } & 1530-2200 \mathrm{~Hz}\end{array}$



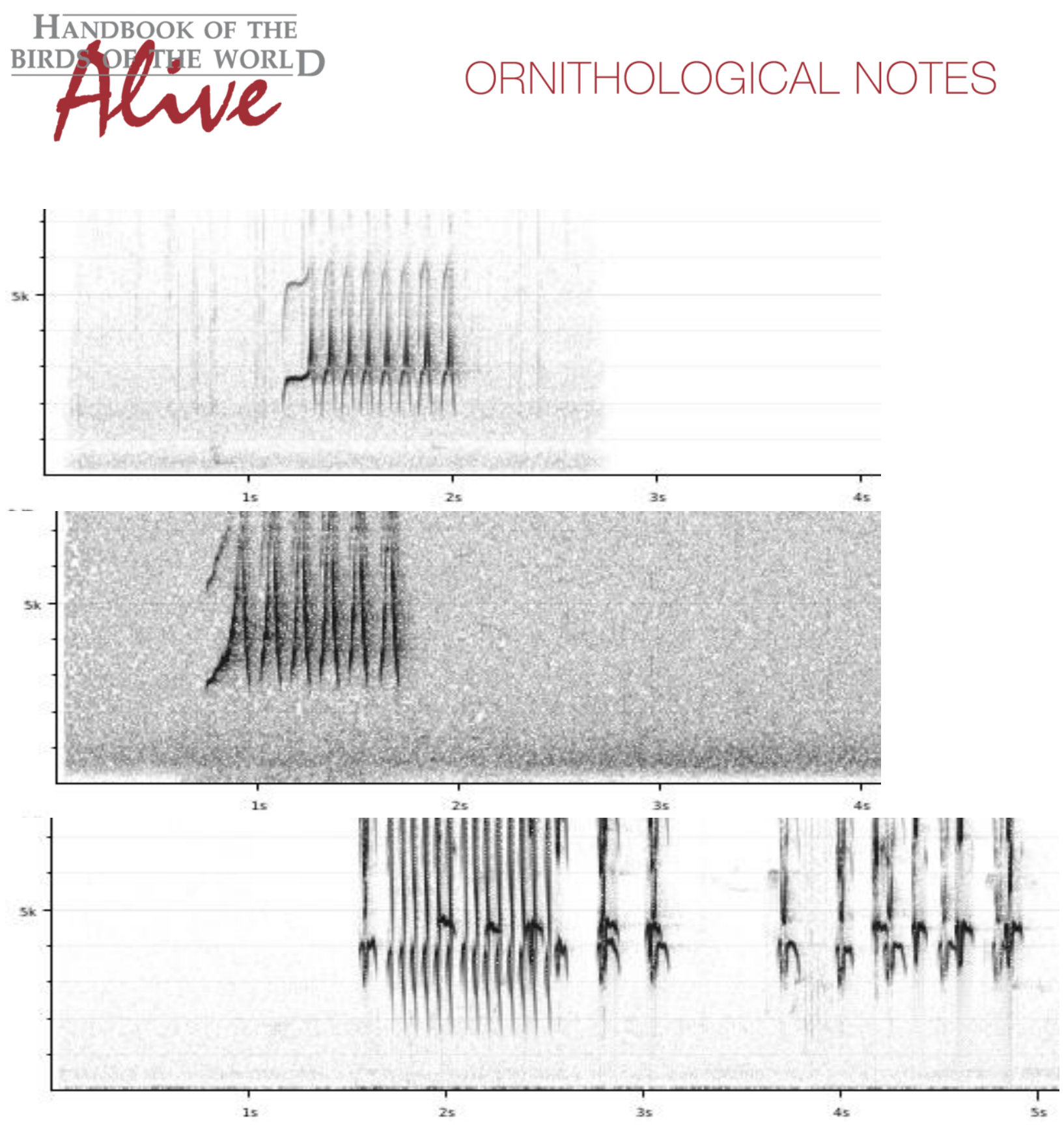

Figure 1: from top to bottom: day-time vocalizations of Group 1, Group 2 and Group 3

Day-time song of crypterythrus differs from all other races by having longer notes (score 2), reaching much higher frequencies (score 2-3) with a very large frequency range (score 2-3) and having a slower pace (score 2-3), which leads to a total vocal score of about 5 by applying Tobias criteria.

Compared to all other races, day-time song of rufescens is structurally quite different (and therefore difficult to score in direct comparison), with usually two birds in asynchronous duet (score 1-2), trill seemingly lacks an initial long note (score 1-2) and number of notes in trill on average higher (score 1-2). Total vocal score therefore at least 3. 
Group 1 and 2 have a day-time song which is structurally very similar. Dawn song is structurally also similar, but again it would seem from available recordings that group 2 (crypterythrus) is higher-pitched, with notes typically above $3 \mathrm{kHz}$, while in group 1 notes typically go down to minimum frequencies of $c 2 \mathrm{kHz}$.

This note was finalized on 2nd July 2015, using sound recordings available on-line at that moment. We would like to thank in particular the many sound recordists who placed their recordings for this species on XC.

\section{References}

Tobias, J.A., Seddon, N., Spottiswoode, C.N., Pilgrim, J.D., Fishpool, L.D.C. \& Collar, N.J. (2010). Quantitative criteria for species delimitation. Ibis 152(4): 724-746.

\section{Recommended citation}

Boesman, P. (2016). Notes on the vocalizations of Bran-colored Flycatcher (Myiophobus fasciatus). HBW Alive Ornithological Note 144. In: Handbook of the Birds of the World Alive. Lynx Edicions, Barcelona. (retrieved from http://www.hbw.com/node/932069 on 16 August 2016). 